\title{
TECNOLOGIA, ESPECIALIZAÇÃO REGIONAL E PRODUTIVIDADE: UM ESTUDO DA PECUÁRIA LEITEIRA EM MINAS GERAIS
}

\author{
Mauro Borges Lemos \& Rangel Galinari \\ Bruno Campos \& Elenice Biasi \& Fabiana Santos
}

(CEDEPLAR/UFMG)

Resumo: Este trabalho pretende estabelecer um comparativo entre algumas microrregiões mineiras produtoras de leite, enfocando, sobretudo, características tecnológicas e de especialização. Trabalha-se com a idéia de que estas variáveis explicam em grande medida o diferencial de produção e produtividade do setor leiteiro, sendo importante o seu entendimento dentro do contexto de intensas mudanças as quais o setor vem passando nos últimos anos no Brasil. Desenvolvendo um estudo de dimensão espacial, pretende-se traçar um perfil da atividade em Minas Gerais, apontando os principais "gargalos" para o seu desenvolvimento e as perspectivas para a redução das desigualdades no setor.

Palavras-chave: pecuária leiteira, tecnologia, análise multivariada.

\section{Introdução}

Grandes transformações têm marcado a produção de leite brasileira nos últimos anos. Tais mudanças estão associadas, principalmente, aos impactos advindos da estabilização monetária, da desregulamentação do mercado (fim do controle estatal sobre os preços), da abertura econômica e da mudança nos padrões de consumo da população, que exigem dos produtores recorrentes adaptações no sentido de se modernizarem, buscando adequar-se à nova conjuntura e melhorar a competitividade. A despeito da queda nos preços ao produtor, a taxa média de crescimento da produção, na década dos 90, foi de $4 \%$ a.a., cifra alcançada, sobretudo, graças às mudanças tecnológi- 
cas que proporcionaram uma redução nos custos de produção (GOMES, 2000).

De acordo com os dados da Pesquisa Pecuária Municipal 2000 do IBGE, o estado de Minas Gerais é o maior produtor de leite do país, com $30 \%$ da produção nacional, enquanto os estados com produção imediatamente inferior - respectivamente Goiás, Rio Grande do Sul e São Paulo - produziram, cada um, cerca de $10 \%$ da produção brasileira.

Em 1994, no estado de Minas Gerais, o número de pequenos e médios produtores de leite (com produção diária de até 50 litros e entre 51 e 200 litros respectivamente) era maior do que o de grandes produtores (produção diária acima de 201 litros), não obstante a maior parte da produção de leite ser proveniente dos médios e grandes produtores, conforme dados da OCEMG (SEBRAE/FAEMG, 1996:13). Em se tratando do tamanho dos estabelecimentos produtores de leite em termos de área (hectares), tem-se que as mesorregiões do Norte, Jequitinhonha/Vale do Mucurí, Triângulo/Alto Paranaíba, Vale do Rio Doce e Noroeste de Minas apresentam, em média, áreas bem superiores às observadas nas demais mesorregiões, superando também a média mineira (SEBRAE/FAEMG, 1996:7).

Em Minas Gerais, a atividade leiteria nos diversos estabelecimentos agropecuários possui distintas finalidades. Coexistem estabelecimentos especializados na atividade, estabelecimentos cuja atividade leiteira exerce a função secundária de viabilizar capital de giro, outros cuja produção de leite é um complemento à atividade principal (cria de bezerros destinados à atividade de engorda e recria), e ainda aqueles nos quais ela se destina à subsistência das famílias. De acordo com o Censo Agropecuário 1995-1996 do IBGE, 71\% da produção mineira é proveniente de estabelecimentos cuja atividade principal é a pecuária, enquanto que $20 \%$ é proveniente de estabelecimentos cuja atividade principal é a produção mista (lavoura e pecuária), sendo o restante distribuído entre os demais. As diferentes distribuições destes tipos de estabelecimentos entre as regiões do estado, em menor ou maior grau, têm uma alta correlação com o desempenho ou a eficiência econômica das mesmas. 
Deve-se frisar também que no estado, bem como no resto do país, há uma tendência de concentração da produção de laticínios em grandes estabelecimentos que lideram a cadeia agro-industrial do leite. Em função disto, a literatura vem considerando correntemente esta indústria como um oligopsônio, o que se configura como parte dos problemas enfrentados pelos produtores de leite, já que esta estrutura de mercado pressiona para baixo o preço do leite recebido pelo produtor.

A partir deste cenário, este artigo propõe um estudo da pecuária leiteira nas microrregiões de Minas Gerais, visando analisar o comportamento destas frente às contínuas transformações citadas acima. Ênfase será dada à capacitação técnica e grau de especialização das mesmas por entendermos que estas características são os principais fatores que explicam as diferenças na produção e na produtividade no setor, sendo capazes de apontar também as microrregiões mais competitivas.

O presente trabalho está subdividido em quatro seções incluindo esta introdução. A seção 2 descreve as bases de dados bem como as metodologias utilizadas. Os resultados são discutidos na seção 3 e por fim, a seção 4 trata das considerações finais.

\section{Base de dados e metodologia}

\subsection{Base de dados}

Para fins de análise, adotou-se como principal base de dados os Censos Agropecuários do IBGE por constituírem fontes consistentes, de boa cobertura e, logo, as mais confiáveis disponíveis na área. Como base de dados complementar foi utilizada a Relação Anual de Informações Sociais (RAIS) 1996.

Vale notar que os Censos Agropecuários apresentam os resultados da pecuária em agregado, isto é, não distinguem informações entre a atividade de corte e a leiteira. De fato, isto constitui um problema, já que em Minas Gerais coexistem as duas formas de exploração em distintas regiões. Assim, algumas variáveis podem não estar representando com tanta fidelidade os reais esforços dedicados à evo- 
lução da atividade leiteira, como os dados de inseminação artificial dos quais não se pode distinguir os empenhos no sentido de se melhorar ou manter o padrão genético mais adequado dos rebanhos para a produção de leite ou de carne. Procurou-se minimizar o problema adotando a microrregião como unidade básica de referência e estudando aquelas em que o peso da atividade leiteira é significativamente maior que o da pecuária de corte. Para tanto, utilizou-se o quociente locacional como forma de identificar o grau de especialização das microrregiões a serem estudadas.

\subsection{O Quociente locacional como índice de especialização}

Existem algumas medidas de natureza setorial que se preocupam com a localização das atividades entre as regiões, vale dizer, procuram identificar padrões de concentração ou dispersão espacial do emprego setorial. O quociente locacional (QL) compara a participação percentual de uma região em um setor particular com a participação percentual da mesma região no total_da economia nacional (Haddad et al., 1989:231-232). O QL superior a 1 em determinado setor sugere que a localidade é exportadora líquida deste bem, denotando, portanto, sua especialização naquele setor de atividade em relação à economia de referência. Assim, optou-se por utilizar o QL para identificar as microrregiões de Minas Gerais onde a atividade leiteira se destaca dentro da produção pecuária total.

Para o cálculo do QL da atividade leiteira nas microrregiões mineiras, foram utilizados os seguintes dados do Censo Agropecuário de 1995-1996: valor total da produção de leite (a atividade) e da produção pecuária (o setor da atividade) em cada microrregião e o valor total das mesmas variáveis para o Brasil.

\subsection{O modelo econométrico}

Com base nos dados do Censo Agropecuário de 1995-96 e da RAIS 1996 (Relação Anual de Informações Sociais), estimou-se uma regressão pelo método dos Mínimos Quadrados Ordinários usando o 
software E-views. Dentre as variáveis disponíveis, foram escolhidas para a regressão aquelas que potencialmente teriam significativo poder para explicar a diferença de produtividade entre as microrregiões. A produtividade (litros/vaca ordenhada/ano) foi tomada como variável dependente e como variáveis independentes foram usados: silagem (capacidade de armazenamento dos silos para forragem aéreos e de encosta/ vacas ordenhadas); o quociente locacional; o percentual de vacas ordenhadas mecanicamente (vacas ordenhadas mecanicamente/total de vacas ordenhadas); o percentual de estabelecimentos com alguma prática de sanidade animal (estabelecimentos informantes de controle de pragas e doenças animal/total de estabelecimentos); e o número de empregados formais na indústria de laticínios. Todas as variáveis foram trasnformadas em seus logaritimos e, assim, assume-se um modelo na forma de duplo-logaritimo. Desta forma, a equação sugerida é:

\section{Ln Prod $=\beta_{1}+\beta_{2}$ Ln Silagem $+\beta_{3} \operatorname{Ln} Q L+\beta_{4}$ Ln Ord. Mecânica $+\beta_{5}$ Ln Sanidade $+\beta_{6}$ Ln Emprego $+\varepsilon$}

A variável proxy de qualidade genética dos rebanhos (bovinos nascidos segundo inseminação artificial/total de bovinos nascidos) foi excluída da regressão para evitar a presença de multicolinearidade. Uma vez que esta apresentou alta correlação com a variável silagem (coeficiente de correlação igual a 0,8), optou-se por manter apenas esta última, dado o seu maior poder explicativo. Todavia, dada a sua importância, aquela variável será explorada na análise multivariada da seção 3 do trabalho.

\subsection{A análise de componentes principais}

Conforme Lemos et al. (2001), uma Análise de Componentes Principais (ACP) procura representar cada microrregião por índices resultantes de adequadas combinações lineares das variáveis econômicas selecionadas. Com esta técnica, além da informação individual de cada índice ou componente principal, tem-se também a informação conjunta de pares de componentes mais importantes na análise. $\mathrm{O}$ 
grau de importância é dado pela magnitude da variância explicada do total de variáveis para cada componente. As variáveis precisam ser correlacionadas no início do processo e o método não requer uma distribuição de probabilidade das variáveis originais.

A ausência de correlação dos índices possibilita medir "dimensões" diferentes nos dados. O primeiro componente principal $\left(Z_{1}\right)$ mostra o maior percentual de variância do conjunto de variáveis explicativas, o segundo componente $\left(Z_{2}\right)$ mostra a segunda maior variância, e assim sucessivamente. Assim, $\operatorname{Var}\left(Z_{1}\right) \geq \operatorname{Var}\left(Z_{2}\right)$ $\geq \ldots \geq \operatorname{Var}\left(\mathrm{Z}_{\mathrm{p}}\right)$, onde $\operatorname{Var}\left(\mathrm{Z}_{\mathrm{i}}\right)$ representa a variância de $\mathrm{Z}_{\mathrm{i}}$ no conjunto de dados considerado. As variâncias de $\mathrm{Z}_{\mathrm{i}}$ são obtidas a partir dos autovalores da matriz de covariância (ou da matriz de correlação). E os elementos dos autovetores, associados a estes autovalores em ordem decrescente, são os coeficientes para os componentes principais.

Cada componente $\mathrm{Z}_{\mathrm{i}}=\mathrm{a}_{1} \mathrm{X}_{1}+\mathrm{a}_{2} \mathrm{X}_{2}+{ }^{\circ}+\mathrm{a}_{7} \mathrm{X}_{7} \mathrm{i}=1, \ldots, 7$ gera uma lista com 41 pontos (cada ponto sendo uma microrregião) obti-

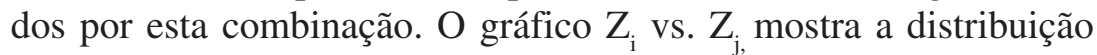
conjunta dos pontos de acordo com os índices obtidos.

A base de dados utilizada na ACP foi a mesma utilizada na regressão, incluindo-se as variáveis mão-de-obra familiar ${ }^{1}$, ordenha manual $^{2}$ (indicativas de atraso da técnica produtiva), inseminação artificial; excluindo-se sanidade e emprego, uma vez que estas possuem baixa correlação com as demais o que piora o poder explicativo dos dois primeiros componentes deste modelo. O procedimento computacional que gerou os resultados da ACP foi o SAS System.

\subsection{A análise de Clusters}

De acordo com Manly (1986), a análise de “clusters" é um método estatístico que possibilita agrupar $n$ objetos em classes, baseadas numa medida de distância (ou grau de similaridade) consideran${ }^{1}$ Com exceção da variável emprego na indústria de laticínios.

${ }^{1}$ Razão entre a variável proprietário e membros não remunerados da família e total de mão-de-obra.

${ }^{2}$ Razão entre vacas ordenhadas com ordenha manuale total de vacas ordenhadas. 
do-se todas as variáveis ao mesmo tempo. A grande vantagem do método é reduzir o volume de informações.

Entre os vários algoritmos propostos para o desenvolvimento da análise de clusters foi escolhida a técnica hierárquica que começa com o cálculo das distâncias de cada indivíduo a todos os outros e assim formando grupos pelo processo de aglomeração. Inicialmente todos os objetos são clusters isolados e, progressivamente, os grupos vão se expandindo até que todos os indivíduos estejam num único cluster. $\mathrm{O}$ método de ligação entre grupos é o group average linkage, que liga dois grupos quando a distância média é bastante pequena. A medida de distância aqui mencionada é a Distância Euclidiana, sendo que, dadas as diferenças de unidade entre as variáveis, todas foram padronizadas. O procedimento computacional utilizado para a padronização e geração do dendograma - o produto final da análise de clusters - foi o SPSS.

\section{Apresentação dos resultados}

\subsection{Configuração Regional da Pecuária Leiteira}

O mapa 1 apresenta a configuração regional definida via cálculo do quociente locacional. Os valores deste variaram de 0,60 a 3,19, sendo que das 66 microrregiões mineiras 41 apresentaram QL superior a 2. Este ponto de corte, que é próximo da média $(2,07)$ e da mediana $(2,14)$ da distribuição dos QLs, foi escolhido por indicar uma forte especialização. 


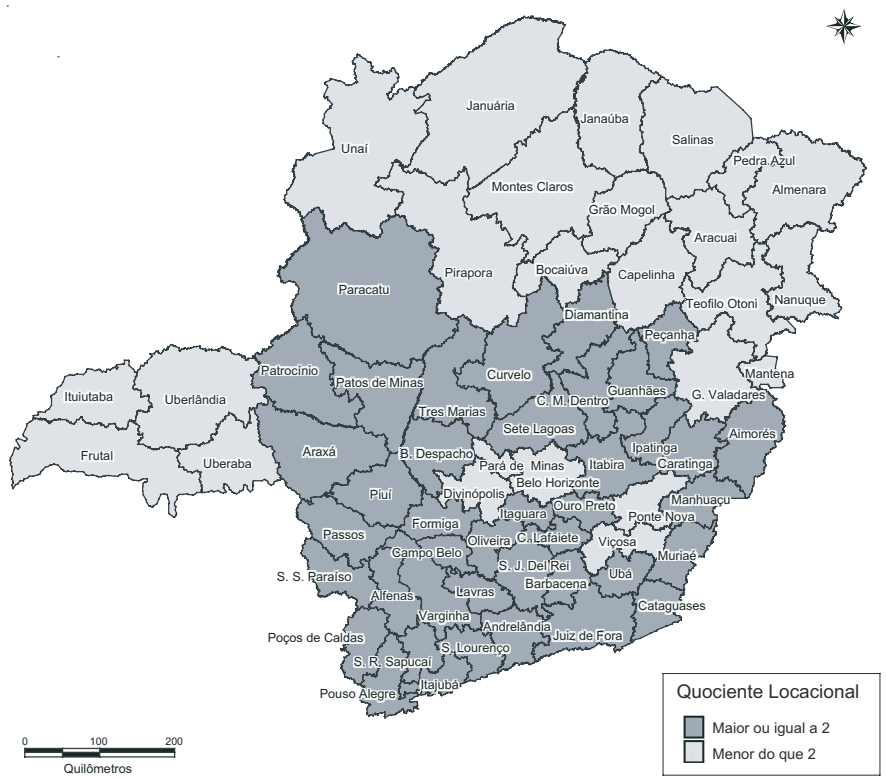

Fonte: CEDEPLAR

\subsection{Eficiência Econômica}

O tradicionalismo presente na produção de leite em Minas Gerais - uma das áreas produtoras mais antigas do país - representa para muitos um fator desfavorável. É comum encontrar na literatura autores que interpretam este tradicionalismo como fonte da refratariedade às inovações tecnológicas e administrativas. Entretanto, conforme será visto nesta seção, o estado tem acompanhado o crescimento produtivo verificado nacionalmente, contrariando esta possível relação determinística.

\subsubsection{Produção e produtividade}

Uma característica notória da produção leiteira no Brasil e que se repete para o estado de Minas Gerais remete à heterogeneidade entre os produtores. Não é difícil encontrar numa mesma microrregião 
desde produtores especializados até pequenos produtores sazonais que fazem da atividade leiteira uma atividade complementar à agricultura ou pecuária de corte.

Para Almeida (2001:118), a cadeia produtiva do leite deverá conservar a tendência de mudanças pelos próximos dez anos, culminando com a especialização maciça, que reduzirá a oferta do produto a um pequeno número de produtores especializados, levando à expulsão de milhares de produtores não especializados. Este processo de exclusão parece ser irreversível, não obstante a possibilidade de mitigar seus custos sociais através de políticas públicas de capacitação, treinamento e reconversão produtiva dos produtores não especializados.

São exatamente os produtores especializados que têm contribuído para melhora significativa da produtividade em praticamente todas as microrregiões mineiras estudadas, através da adoção de técnicas e métodos modernos como silagem, ordenha mecânica, resfriamento, granelização e melhoria genética do rebanho.

A Tabela 1 do Apêndice traz os dados de produção e produtividade para as microrregiões em análise no período inter-censitário. Os resultados corroboram o bom desempenho do estado, e em especial das microrregiões estudadas, na evolução da produção leiteira. Mesmo levando-se em conta que algumas microrregiões apresentam uma base produtiva ainda pequena, o que poderia enviesar a análise, não se pode desprezar o fato de que mais da metade das microrregiões especializadas apresentaram crescimento da produção acima da média estadual. Tal crescimento se deve, em grande medida, à adoção de tecnologias que melhoraram a produtividade, a qual também cresceu significativamente.

Chamam a atenção os baixos níveis de crescimento de algumas das mais tradicionais microrregiões produtoras de leite no estado, em especial Poços de Caldas, Pouso Alegre, Andrelândia, Araxá e Juiz de Fora, que apresentaram um crescimento abaixo das médias estadual e nacional. Tal fato pode estar sinalizando que estas regiões atingiram a maturidade produtiva há mais tempo e passam por um período de poucas inovações, possibilitando que outras microrregiões 
as alcancem (como Bom Despacho, Piuí, Passos, Patrocínio, Patos de Minas e Paracatu).

\subsubsection{Fatores explicativos para as diferenças de produtividade entre as microrregiões}

O resultado da regressão, conforme pode ser visto na Tabela 1, confirma a importância da especialização para a melhoria da produtividade no setor. Dentre as variáveis explicativas, merece destaque a silagem que figura como uma das principais variáveis tecnológicas e reflete, em grande medida, o grau de especialização da microrregião e sua capacidade de sustentar relativa homogeneidade na produção ao longo do ano.

A variável ordenha mecânica, apesar de menos significativa entre as variáveis utilizadas (provavelmente em função de sua baixa difusão), influencia a produtividade animal, além de ser um bom indicativo da modernização da microrregião e da qualidade do leite produzido pela mesma. Sua incidência remete à existência de grandes produtores (dada sua alta exigência de capitalização), especializados em sua maioria.

\section{Tabela 1: Fatores explicativos do diferencial de produtividade entre as microrregiões estimados pelo MQO}

\begin{tabular}{lrrrr}
\hline \multicolumn{1}{c}{ Variável } & Coeficiente & Desvio Padrão & \multicolumn{1}{c}{-Statistic } & Prob. \\
\hline C & 4,798278 & 0,333031 & 14,40791 & 0,0000 \\
LN_SILAGEM & 0,108005 & 0,015011 & 7,19495 & 0,0000 \\
LN_QL & 0,439569 & 0,118595 & 3,70646 & 0,0007 \\
LN_ORD_MEC & 0,114824 & 0,035821 & 3,20546 & 0,0029 \\
LN_SANIDADE & 0,253466 & 0,081295 & 3,11785 & 0,0036 \\
LN_EMP & 0,024399 & 0,010618 & 2,29789 & 0,0277 \\
\hline$R^{2}$ ajustado $=0,84$ & & \multicolumn{3}{c}{ F-statistic $=44,693$} \\
\hline
\end{tabular}

Fonte: Ela boração Própria a partir dos dados de IBGE - Censo Agropecuário 1995-96, MTE/FAT Rais 1996.

Obs. Heterocedasticidade testada pe lo Teste de White, além da análise gráfica dos resíduos. Ambos os procedimentos apontaram para homocedasticidade do modelo. 
A inclusão do quociente locacional, por sua vez, reflete a influência do grau de especialização da microrregião sobre a produtividade. Esta variável atua positivamente sobre a produtividade através das economias de escala e de aglomeração advindas da maior especialização e concentração espacial dos produtores.

O objetivo de incluir a variável sanidade é reafirmar a importância do cuidado sanitário para assegurar uma boa produtividade. A variável que mede o emprego formal da indústria tenta, por sua vez, medir a complementaridade da cadeia produtiva dentro da microrregião. Sua contribuição à produtividade parece estar associada à interação entre os setores primário e secundário no sentido de prover economias de escala relacionadas à assistência técnica, controle de qualidade, incentivo à modernização etc.

Apesar da indisponibilidade de dados referentes à granelização e ao uso de resfriadores, não se pode deixar de destacar a importância dessas técnicas, que certamente representam uma tendência de especialização do setor, consonante com o resultado da regressão. Em grande medida, tal resultado está em conformidade com as proposições de Almeida (2001), que prevê, para o longo prazo, uma concentração da produção em torno de um número reduzido de produtores especializados, que tendem a substituir de forma efetiva os produtores não especializados.

\subsection{Distribuição Espacial dos Fatores Tecnológicos}

A abordagem anterior, através de um modelo de regressão, estabeleceu uma relação de dependência entre a variável produtividade e as variáveis que a influenciam. A próxima abordagem, através de duas técnicas não paramétricas de análise multivariada, procura caracterizar as microrregiões de acordo com sua distribuição multivariada. A primeira, a Análise de Componentes Principais, é utilizada para demonstrar a distribuição espacial da tecnologia empregada na atividade leiteira entre as microrregiões pari passu com o grau de especialização das mesmas na atividade. A segunda, a Análise de Cluster, é utilizada para agrupar microrregiões de acordo com algumas variáveis-chave da atividade. 


\subsubsection{A análise de componentes principais (ACP)}

O resultado da análise multivariada permite observar a distribuição espacial das microrregiões estudadas segundo os fatores tecnológicos empregados na produção de leite, bem como a especialização das mesmas na atividade, através de uma interpretação conjunta das sete variáveis disponíveis no Censo Agropecuário de 1995-1996, consideradas de grande relevância para a caracterização regional.

$\mathrm{Na} \mathrm{ACP}$, as características predominantes em cada componente ficam determinadas pelo valor dos coeficientes associados às variáveis possibilitando assim a classificação das microrregiões. O número de componentes é escolhido pela maior variação acumulada. Neste caso, foram escolhidos os dois primeiros componentes, com $78 \%$ da variância dos dados, sendo 59\% do primeiro componente.

A Tabela 2 mostra os coeficientes de todos os componentes, e verifica-se que, no componente 1 , os maiores valores estão associados às variáveis que demonstram o maior ou menor emprego de práticas e instrumentos de cunho tecnológico, podendo ser chamado de componente ou eixo da tecnologia (estando aí incluída a produtividade animal, pois esta possui alta correlação com as variáveis de modernização). Já no segundo componente, a variável QL domina, sendo então denominado componente ou eixo da especialização.

\section{TABELA 2: Coeficientes das combinações lineares da ACP}

\begin{tabular}{lccccccc}
\hline & \multicolumn{7}{c}{ Autovetores } \\
\cline { 2 - 8 } Variáveis & Prin 1 & Prin2 & Prin3 & Prin4 & Prin5 & Prin6 & Prin7 \\
\hline Produtividade & 0,432150 & 0,220823 & 0,112077 & 0,134912 & 0,663414 & 0,553317 & 0,000000 \\
Ord Mecânica & 0,410219 & $-0,411817$ & $-0,238959$ & 0,281582 & 0,156225 & $-0,036486$ & 0,707107 \\
silagem & 0,380410 & 0,314499 & 0,474151 & 0,296023 & $-0,130738$ & $-0,653328$ & 0,000000 \\
Insem Artificial & $-0,390569$ & 0,331608 & 0,305806 & $-0,146596$ & 0,675687 & 0,407347 & 0,000000 \\
Ord Manual & $-0,410219$ & 0,411817 & 0,238959 & $-0,281582$ & $-0,156225$ & 0,036486 & 0,000000 \\
M O Familiar & $-0,404438$ & 0,203856 & 0,024316 & 0,844699 & 0,167649 & 0,229474 & 0,707107 \\
QL & 0,125942 & 0,601348 & $-0,752905$ & $-0,024204$ & 0,096527 & $-0,213893$ & 0,000000 \\
\hline
\end{tabular}

O Gráfico 1 mostra a distribuição das microrregiões segundo seus valores nos dois primeiros componentes principais. Os 
vetores representam a direção das variáveis em questão e a maior representatividade destas nos eixos também pode ser medida através da maior distância ortogonal do vetor em relação aos mesmos. Da análise do eixo 1 ("dimension 1") é possível perceber as diferenças de distribuição da tecnologia empregada na pecuária leiteira no espaço mineiro. As microrregiões localizadas na parte positiva de tal eixo são aquelas que apresentaram relativamente maiores estoques de fatores tecnológicos em 1995-1996 e consequentemente maior produtividade, já que, como mostrado Seção 3.2.2, o maior ou menor empenho de capital desta natureza responde por grande parte da variância de produtividade observada entre as microrregiões.

Ainda no componente 1, percebe-se, na parte positiva do eixo, que há uma grande participação das microrregiões do sul/sudoeste do estado, que é uma das bacias leiteiras mais tradicionais do país. Portanto, este fato desmistifica a questão do tradicionalismo como fonte de refratariedade às inovações. Já a parte negativa do componente 1 mostra as microrregiões que, em 1995-1996, possuíam baixos investimentos em tecnologia, ou seja, maior empenho em práticas mais rudimentares, que, se por um lado, onera a produtividade e a qualidade do leite, por outro, permite que estas operem com baixos custos. Entretanto, não se deve perder de vista que ganhos de produtividade proporcionam também reduções de custos. 


\section{GRÁFICO 1: Componentes principais: as dimensões representa- tivas da tecnologia e especialização}

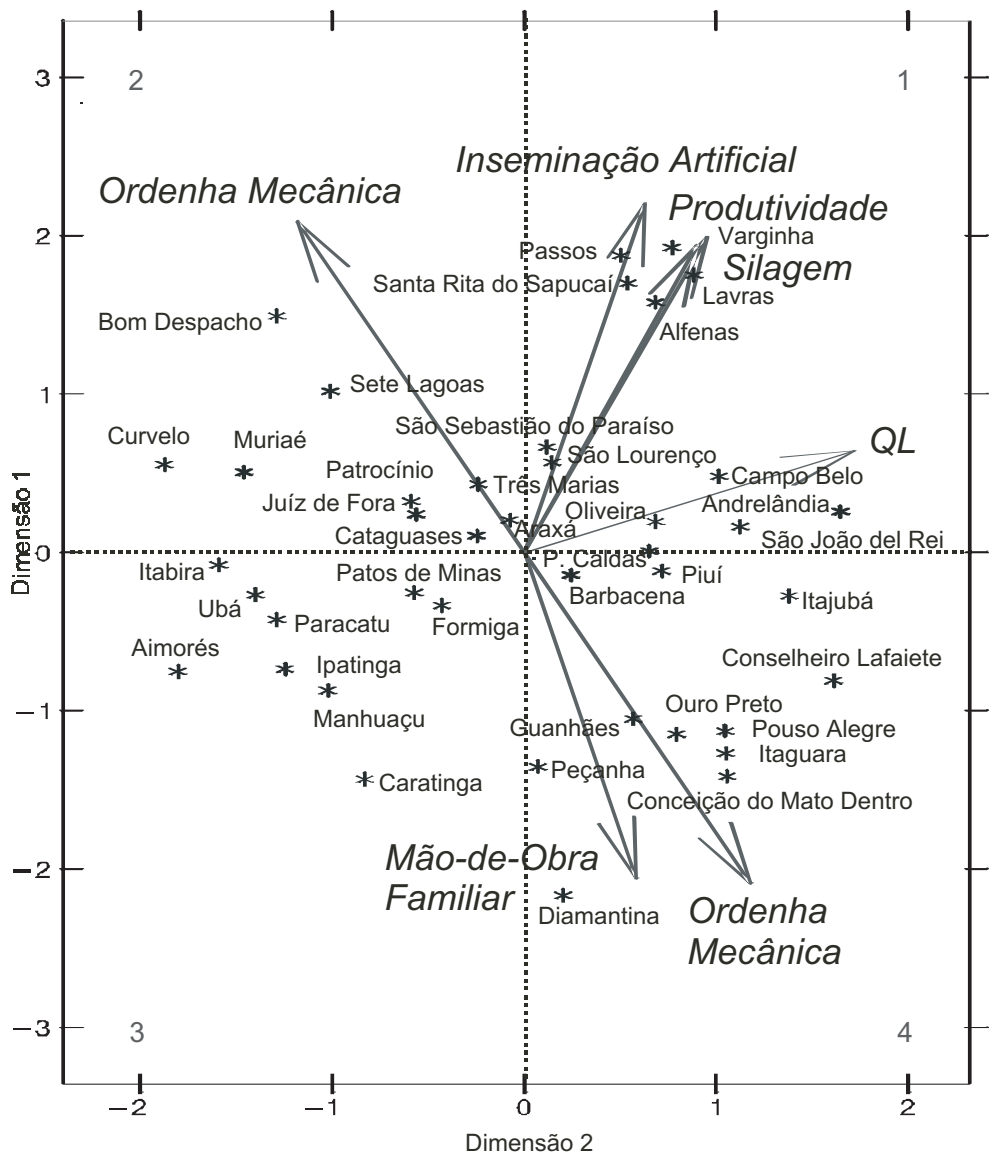

É importante frisar que quanto mais distante as microrregiões estão do centro do componente, que é o locus da média da nuvem de dados, mais forte é a característica positiva ou negativa focada no estudo. Deste modo, é possível perceber que as microrregiões de Passos, Varginha, Lavras, Alfenas, Santa Rita do Sapucaí e Bom Despacho ocupam uma posição de primazia, em se tratando de tecnologia e 
produtividade na atividade leiteira, enquanto que Diamantina, Caratinga, Peçanha, Conceição do Mato Dentro e Itaguara ocupam as posições menos favoráveis.

Quanto ao segundo componente (“dimension 2"), tem-se, na sua parte positiva, as microrregiões mais especializadas na produção de leite em relação à produção pecuária total. A análise deste componente deve ser feita com cautela, pois algumas microrregiões que se mostram especializadas o são devido à suas baixas escalas de produção pecuária e que, portanto, torna a produção de leite, mesmo que pouco significativa, aparentemente importante no contexto mineiro. O mesmo pode ser dito para algumas microrregiões com grande expressão na atividade leiteira e que apresentam baixos QLs em função de sua maior diversificação produtiva. Não obstante, a análise dos dois componentes em conjunto permite que se identifiquem quais microrregiões são verdadeiramente especializadas.

Os pontos do gráfico localizados na interseção das áreas positivas de ambos os eixos (quadrante 1) representam as microrregiões que combinam as melhores condições de produção, isto é, tecnologia e especialização. Nestas estão sobrepostos maiores empenhos de capital em fatores que garantem mais efetividade à produtividade animal, representados pela prática de inseminação artificial, que permite a constituição de rebanhos com um padrão genético, que combina doses certas de produtividade e robustez (padrão girolanda), e a prática de silagem, que é responsável por uma maior estabilidade do nível de produção durante todo o ano. Já o maior grau de especialização é um indicativo de que as microrregiões aí localizadas dedicam-se mais à atividade leiteira em relação às demais atividades da pecuária, de forma que podem garantir benefícios proporcionados por economias de especialização, aglomeração e aprendizado por interação. Das microrregiões aí localizadas, Varginha, Passos, Santa Rita do Sapucaí, Lavras e Alfenas são os expoentes mineiros nestes aspectos, enquanto que as demais, apesar de ainda muito expressivas, estão mais próximas da média das microrregiões em estudo.

Em contraposição àquelas microrregiões, as localizadas na sobreposição das áreas negativas de ambos os eixos, quadrante 3, re- 
únem as piores condições de produção. Vale frisar que as microrregiões de Paracatu e Patos de Minas, apesar de possuírem uns dos maiores níveis de produção do estado, estão aí localizadas. Tal fato é assegurado pelo grande número de animais, mas isto não é suficiente para garantir eficiência. $\mathrm{O}$ baixo desempenho relativo da produtividade das mesmas se deve ao fato de empregarem, na grande maioria das propriedades, sistemas de produção atrasados e pelo menor grau de especialização na atividade. Este último é um reflexo de sua posição geográfica limítrofe entre a bacia leiteira do Sul/Sudoeste, Triângulo e Norte do estado que são mais especializados na atividade de corte. Portanto, a grande presença nestas microrregiões de estabelecimentos que se dedicam à cria de animais destinados às regiões de engorda, cujas matrizes são predominantemente da raça nelore, também é um fator que influencia negativamente o desempenho da atividade leiteira das mesmas.

O quadrante 2 do Gráfico 1, onde se sobrepõe a seção positiva do eixo da tecnologia e a negativa do eixo da especialização, reúne microrregiões produtivas com maior diversificação da produção pecuária e fortemente influenciadas pelo vetor que representa a prática de ordenha mecânica (incentivada por grandes laticínios locais), o que indica que nestas há uma grande preocupação com a qualidade do leite produzido. Destacam-se aí as microrregiões de Bom Despacho e Sete Lagoas. Neste quadrante está localizada a microrregião de Patrocínio com características semelhantes às observadas em Paracatu e Patos de Minas - quanto à localização geográfica e presença de atividade de cria - sinalizando que a mesma está transitando em direção à modernização do processo produtivo.

Por fim, no quadrante 4, onde se sobrepõem menores indicativos de modernização e concentração da atividade relativamente elevada, coexistem dois conjuntos de microrregiões. De um lado, observam-se microrregiões em que a produção de leite, em termos absolutos, é pequena, mas significativa em relação à reduzida produção pecuária da microrregião (como nos casos de Ouro Preto e Diamantina) e, por isso, tornam-se aparentemente importantes no contexto estadual. De outro, observam-se microrregiões cuja produção é mais ex- 
pressiva no contexto estadual, mas que apresentam empenhos menores em fatores tecnológicos e, portanto, desempenhos também pouco importantes em produtividade.

\subsubsection{A análise de clusters}

O Diagrama 1 é o resultado da análise de clusters para as variáveis utilizadas na regressão e $\mathrm{ACP}^{1}$ devidamente padronizadas. A escala, que varia de 0 a 25, representa o grau de similaridade entre as microrregiões estudadas, sendo que esta aumenta à medida que a escala se reduz. Percebe-se que em 1995/96, na escala 5 (escala que representa $20 \%$ da maior distância onde todas as microrregiões formam um único cluster), as microrregiões de Alfenas, Varginha, Santa Rita do Sapucaí, Passos e Lavras formam um cluster, que incorpora Bom Despacho na escala 15. Conforme pode ser observado na ACP, este cluster ocupa a primazia em Minas Gerais em se tratando de fatores tecnológicos instalados, especialização e produtividade na produção de leite. É interessante notar que tal aglomeração possui uma contigüidade geográfica, o que cria um ambiente propício à instalação de empresas dos demais elos produtivos da cadeia agro-industrial do leite. No contexto da inserção regional brasileira, conforme definido por Lemos et al. (2000), esta é uma mesorregião mineira diretamente polarizada pelo macropólo de São Paulo, o que facilita seu acesso aos insumos e métodos de manejo da fronteira tecnológica do setor e ao maior mercado regional de laticínios do país, dado pela Região Metropolitana de São Paulo. Portanto, neste aglomerado há potencial de formação de um cluster espacial laticinista, tecnologicamente mais avançado, que poderia ser objeto de uma política regional por trazer benefícios econômicos e sociais.

Sob a mesma escala que o cluster anterior, nota-se a formação de um cluster composto pelas microrregiões de Itaguara, Pouso Alegre, Conselheiro Lafaiete, Ouro Preto, Peçanha, Guanhães e Conceição do Mato Dentro. Conforme pode ser visto na ACP, esta aglomeração é formada por microrregiões onde há baixos empenhos em fatores tecnológicos e uma falsa impressão de especialização, em função 
da pequena base produtiva pecuária das mesmas. Este cluster, que reúne comunalidades de baixa tecnologia, não constitui uma mesma aglomeração espacial contígua, apesar das microrregiões nele agrupadas serem áreas de influência do macropólo de Belo Horizonte, com exceção de Pouso Alegre.

\section{DENDOGRAMA 1: Agrupamento das microrregiões segundo as variáveis representativas da tecnologia , especialização e produti- vidade via análise de clusters}

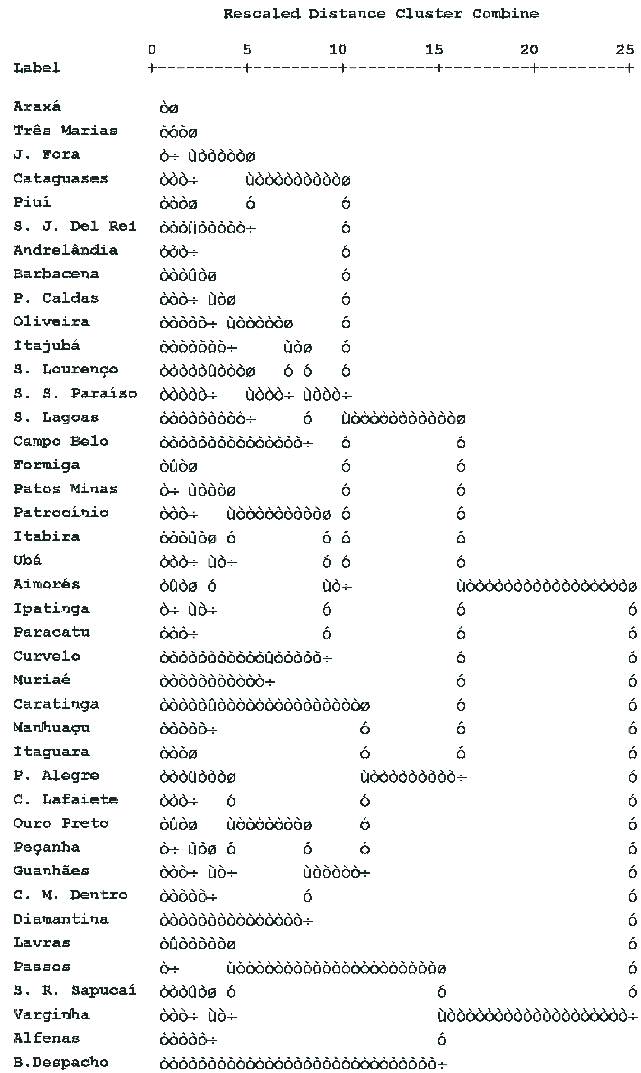


Outro cluster de baixa tecnologia e especialização, constituído por volta da escala 5, é composto pelas microrregiões de Formiga, Patos de Minas, Patrocínio, Itabira, Ubá, Aimorés, Ipatinga e Paracatu. Do ponto de vista regional, sua inserção é também espacialmente descontínua: as microrregiões de Patos de Minas e Patrocínio pertencem ao mesopólo de Uberlândia, sob a área de influência de São Paulo; Paracatu é polarizada por Brasília; Aimorés e Ubá são polarizadas pelo Rio de Janeiro e as demais microrregiões por Belo Horizonte.

O cluster formado próximo à escala 7 , reunindo as microrregiões de Barbacena, Poços de Caldas, Oliveira, Itajubá, São Lourenço, São Sebastião do Paraíso e Sete Lagoas, também pode ser considerado um cluster espacial, com exceção da microrregião de Sete Lagoas. Em termos espaciais, sua inserção regional assemelha-se ao primeiro analisado, estando também em grande parte sob a área de influência do Macropólo de São Paulo. Em termos tecnológicos, por sua vez, percebe-se que este possui uma interpretação parecida com um outro cluster formado, sob a escala 5, pelas microrregiões de Araxá, Três Marias, Juiz de Fora, Cataguases, Piuí, São João Del Rei e Andrelândia. Ou seja, são aglomerações com graus de especialização razoavelmente diversificados, mas que representam a posição média da adoção de tecnologia na pecuária leiteira pelas microrregiões mineiras.

Por fim, deve-se ressalvar que algumas microrregiões se ligam a estes clusters a uma escala maior, revelando que estas possuem padrões particulares no contexto mineiro em se tratando dos aspectos produtivos da pecuária leiteira.

\section{Considerações Finais}

A pecuária leiteira em Minas Gerais comporta uma certa diversidade de padrões de produção. Uma primeira distinção foi realizada entre microrregiões exportadoras líquidas da produção leiteira (especializadas) e as importadoras (não-especializadas), através do cálculo do quociente locacional. Este indicador mostrou que o centro-sul do estado apresenta considerável especialização na pecuária leiteira, em contraste com o norte do estado. 
A partir desta distinção, foi possível delimitar diferentes padrões de produção, dentre as microrregiões especializadas, com base na distribuição espacial dos fatores tecnológicos. Observou-se, com a utilização das técnicas de ACP e Análise de Clusters, a existência de dois grandes grupos de produtores (Diagrama 1, escala 15), com o claro predomínio daquele que reúne comunalidades de média/baixa tecnologia e especialização. A escalas inferiores, é possível distinguir, dentro deste grande grupo, padrões de produção diferenciados em termos de sua posição na adoção de tecnologia (baixa ou média) e da relevância dos distintos fatores tecnológicos. Não existe, porém, uma aderência territorial deste agrupamento de média/baixa tecnologia, pois suas microrregiões não constituem um cluster espacial, mas estão dispersas territorialmente no todo estadual.

O segundo grande grupo de produtores é constituído pela mais tradicional bacia leiteira do estado (formada pelas microrregiões de Lavras, Passos, S. R. Sapucaí, Varginha e Alfenas), que se constitui em um efetivo cluster espacial. Paradoxalmente, esta tem sido capaz de sustentar elevados níveis de produtividade, refletindo a sua primazia em termos de fatores tecnológicos instalados e especialização. Neste caso, parecem ser importantes não somente os ganhos advindos de economias de escala e aglomeração, mas também os esforços de atualização tecnológica dos produtores, resultantes de sua posição geográfica privilegiada. De fato, esta região é diretamente influenciada pelo macropólo de São Paulo e, por isso, se beneficiou, ao longo dos anos, do fácil acesso à oferta de insumos e ao maior mercado regional de laticínios do país; da disponibilidade de informações sobre tecnologias avançadas de manejo; e dos efeitos de transbordamento e relocalização das grandes indústrias laticinistas de São Paulo.

Esta grande heterogeneidade da pecuária leiteira de Minas Gerais coloca grandes desafios aos gestores públicos e agentes privados (notadamente a indústria laticinista) na elaboração e implementação de políticas de âmbito regional voltadas para a modernização e redução das desigualdades intra-setoriais. Sem dúvida, é de fundamental importância para o enfretamento destes desafios o estabelecimento de padrões regionais de eficiência comparativa. Neste sentido, 
o este estudo pode ser visto como uma tentativa de contribuir para a identificação de padrões de eficiência comparativa da pecuária leiteira entre microrregiões de Minas Gerais.

\section{Referências Bibliográficas}

ALMEIDA, E. F. L. Aspectos Sociais da Produção de Leite no Brasil. In: MADALENA, F. E.; MATOS, L. L.; HOLANDA JR., E. V. (editores). Produção de Leite e Sociedade: uma análise crítica da cadeia do leite no Brasil. Belo Horizonte: FEPMVZ, 2001.

GOMES, S. T. Economia da Produção do Leite. Belo Horizonte: Itambé, Dez/2000.

HADDAD, P.R. (org). Economia Regional: teorias e métodos de análise. Fortaleza: BNB/ETENE, 1989.

LEMOS, M.B.; GUERRA, L.P.; MORO, S. “A nova configuração regional brasileira: sua geografia econômica e os determinantes locacionais da indústria". Campinas: Anais do XXVIII Encontro Nacional de Economia - ANPEC: 2000.

LEMOS, M.B. et al. "A Dinâmica Urbana das Regiões Metropolitanas Brasileiras". Salvador: Anais do XXIX Encontro Nacional de Economia - ANPEC: 2001.

MANLY, B. F. J. Multivariate Satistical Methods: A Primer. New York: Chapman and Hall, 1986.

SEBRAE-MG/FAEMG. Diagnóstico da Pecuária Leiteira do Estado de Minas Gerais. Belo Horizonte: SEBRAE-MG, 1996. 


\section{APÊNDICE:}

\section{TABELA 1: Produção e produtividade da atividade leiteira (1985 e 1995-96)}

\begin{tabular}{|c|c|c|c|c|c|c|}
\hline \multirow{2}{*}{ Microrregião } & \multicolumn{2}{|c|}{1985} & \multicolumn{2}{|c|}{$1995-1996$} & \multirow{2}{*}{\begin{tabular}{|c|} 
Variação \\
Produção (\%)
\end{tabular}} & \multirow{2}{*}{$\begin{array}{c}\text { Variação } \\
\text { Produtiv. (\%) } \\
\end{array}$} \\
\hline & Produção (Mil l) & Produtividade & Produção (Mil l) & Produtividade & & \\
\hline Aimorés & 83.421 & $1.030,46$ & 93.345 & $1.197,63$ & 11,90 & 16,22 \\
\hline Alfenas & 70.533 & $1.421,61$ & 113.946 & $2.087,39$ & 61,55 & 46,83 \\
\hline Andrelândia & 105.813 & $2.306,95$ & 87.918 & $2.001,97$ & $-16,91$ & $-13,22$ \\
\hline Araxá & 152.839 & $1.395,48$ & 206.791 & $1.983,36$ & 35,30 & 42,13 \\
\hline Barbacena & 41.010 & $1.479,44$ & 53.861 & $1.698,02$ & 31,34 & 14,77 \\
\hline Bom Despacho & 109.251 & $1.421,54$ & 212.541 & $2.170,40$ & 94,54 & 52,68 \\
\hline Campo Belo & 33.010 & $1.384,65$ & 47.697 & $1.963,82$ & 44,49 & 41,83 \\
\hline Caratinga & 41.289 & 929,66 & 38.011 & $1.083,84$ & $-7,94$ & 16,58 \\
\hline Cataguases & 77.604 & $1.518,02$ & 100.664 & $1.819,01$ & 29,71 & 19,83 \\
\hline Conc. Mato Dentro & 26.125 & $1.009,97$ & 39.368 & $1.326,37$ & 50,69 & 31,33 \\
\hline Cons. Lafaiete & 21.200 & $1.175,88$ & 39.119 & $1.740,88$ & 84,52 & 48,05 \\
\hline Curvelo & 59.304 & 991,92 & 89.067 & $1.543,00$ & 50,19 & 55,56 \\
\hline Diamantina & 5.255 & 726,13 & 5.410 & 831,74 & 2,96 & 14,54 \\
\hline Formiga & 42.864 & $1.089,55$ & 72.760 & $1.637,16$ & 69,75 & 50,26 \\
\hline Guanhães & 38.393 & 971,80 & 57.659 & $1.344,06$ & 50,18 & 38,31 \\
\hline Ipatinga & 19.395 & $1.031,32$ & 21.115 & $1.208,50$ & 8,87 & 17,18 \\
\hline Itabira & 42.939 & $1.106,05$ & 60.944 & $1.457,74$ & 41,93 & 31,80 \\
\hline Itaguara & 24.839 & $1.239,35$ & 34.287 & $1.569,07$ & 38,04 & 26,60 \\
\hline Itajuba & 43.837 & $1.303,55$ & 49.536 & $1.536,47$ & 13,00 & 17,87 \\
\hline Juiz de Fora & 119.369 & $1.342,34$ & 147.003 & $1.713,64$ & 23,15 & 27,66 \\
\hline Lavras & 55.873 & $1.697,08$ & 84.238 & $2.399,93$ & 50,77 & 41,42 \\
\hline Manhuaçu & 29.162 & 985,47 & 32.349 & $1.154,30$ & 10,93 & 17,13 \\
\hline Muriaé & 67.854 & $1.399,80$ & 89.266 & $1.612,35$ & 31,56 & 15,18 \\
\hline Oliveira & 56.377 & $1.429,94$ & 84.144 & $1.946,65$ & 49,25 & 36,13 \\
\hline Ouro Preto & 8.213 & $1.127,23$ & 7.880 & $1.410,90$ & $-4,06$ & 25,17 \\
\hline Paracatu & 113.896 & 831,10 & 188.106 & $1.469,12$ & 65,16 & 76,77 \\
\hline Passos & 83.493 & $1.380,21$ & 184.497 & $2.415,80$ & 120,97 & 75,03 \\
\hline Patos de Minas & 124.955 & $1.059,18$ & 208.388 & $1.874,82$ & 66,77 & 77,01 \\
\hline Patrocínio & 107.480 & 982,22 & 222.487 & $1.941,12$ & 107,00 & 97,63 \\
\hline Peçanha & 38.805 & $1.182,50$ & 50.244 & $1.268,66$ & 29,48 & 7,29 \\
\hline Piuí & 69.471 & $1.104,71$ & 120.821 & $1.752,45$ & 73,92 & 58,63 \\
\hline Poços de Caldas & 76.661 & $1.449,03$ & 94.701 & $1.716,78$ & 23,53 & 18,48 \\
\hline Pouso Alegre & 71.450 & $1.265,30$ & 75.532 & $1.395,19$ & 5,71 & 10,27 \\
\hline Sta. Rita Sapucaí & 51.981 & $1.462,52$ & 88.351 & $2.000,44$ & 69,97 & 36,78 \\
\hline São Joao Del Rei & 53.596 & $1.269,51$ & 100.708 & $1.972,27$ & 87,90 & 55,36 \\
\hline São Lourenço & 72.404 & $1.502,16$ & 92.109 & $1.910,51$ & 27,22 & 27,18 \\
\hline S Sebastião Paraíso & 70.115 & $1.353,26$ & 107.291 & $1.955,61$ & 53,02 & 44,51 \\
\hline Sete Lagoas & 78.387 & $1.414,80$ & 134.382 & $2.242,28$ & 71,43 & 58,49 \\
\hline Três Marias & 44.960 & $1.029,54$ & 118.444 & $2.053,33$ & 163,44 & 99,44 \\
\hline Ubá & 48.392 & $1.363,88$ & 71.070 & $1.615,81$ & 46,86 & 18,47 \\
\hline Varginha & 100.352 & $1.494,58$ & 151.910 & $2.118,90$ & 51,38 & 41,77 \\
\hline Micros Selec. & 2.582 .167 & $1.249,18$ & 3.877 .961 & 1783,09 & 50,18 & $\overline{42,74}$ \\
\hline MINAS GERAIS & 3.772 .411 & $1.091,16$ & 5.499 .862 & 1605,04 & 45,79 & $\overline{47,10}$ \\
\hline BRASIL & 12.846 .432 & 959,77 & 17.931 .249 & 1306,69 & 39,58 & 36,15 \\
\hline
\end{tabular}

Fonte: IBGE - Censos Agropecuários 1985 e 1995-96. 